\title{
Human Machine Interaction (HMI) in Offshore Drilling - oil rig workers' opinion about their interaction with machines
}

\author{
Siddique $\mathbf{A H}^{1,5}$, Shamsi $\mathbf{T}^{2^{*}}$, Hasan $\mathbf{M}^{3,4}$ \\ ${ }^{1}$ Department of Health, Safety and Environment Engineering, Khalifa University, Abu Dhabi 127788, UAE, \\ ${ }^{2}$ Independent Public Health Researcher, Apartment C2 House 63 Road 25 Block A Banani 1213, Dhaka, \\ ${ }^{3}$ Department of Electrical and Computer Engineering, North South University, Dhaka 1229, Bangladesh, ${ }^{4}$ Faculty \\ of Science, Engineering and Technology, University of Science and Technology Chittagong, Chattogram \\ 4202, Bangladesh, ${ }^{5}$ Faculty of Electrical Engineering, The International University of Scholars, Banani, Dhaka, \\ Bangladesh
}

\section{ABSTRACT}

Introduction: There are huge numbers of drilling platforms in the world and if once the worker on those platforms meets with an accident, the situation could be very serious. The consequence of this could be environmental, economic and in some cases fatal. Middle East, being one of the oil rich regions has some of the largest operators. The companies own various types of jack up rigs ranging from old generation rigs to the latest cyber-rig. This paper addresses what oil rig workers have to say about their interaction with machines, and how Human Machine Interaction (HMI) in Offshore Drilling can be improved with design.

Methods: A case study approach was undertaken. The analysis in this paper draws on the interviews conducted with two different employees involved in operating the drilling operations conducted in the driller's cabin of newly designed offshore rigs. A semi-structured approach was adopted, using themes identified through analysis of the preceding. The interviews were transcribed by the research team. Each interview was analyzed thematically with existing system and reported discrepancy

Results: The study on Human Machine Interaction (HMI) and Human Factor regarding this has been conducted in the latest generation cyber rigs. There are many aspects of $\mathrm{HMI}$ and ergonomics but in this study a special concentration has been given to deal with the ergonomic standpoint and evaluates the drillers console controls. Conclusion: When comparison is done with the existing machinery, few modifications can be thought of for better human machine interaction. A better human machine interaction system can ensure a productive environment for the oil-rig workers.

Key words: Control panel, Ergonomics, Human factors, Human machine interaction, Offshore drilling,

Practitioner Summary: In this study, a special concentration has been given to deal with the ergonomic standpoint and evaluates the drillers console controls. The discussions put forward in this paper will ensure a better human machine interaction interface in oilrig platforms.

DOI: https://doi.org/10.3126/ijosh.v11i3.39812

Conflicts of interest: None

Supporting agencies: None

Date of submission: 11.07.2021

Date of acceptance: 03.09.2021

Date of publication: 30.09 .2021

\section{Corresponding Author}

Ms. Tasdidaa Shamsi,

Independent Public Health Researcher,

Apartment C2 House 63 Road 25 Block A Banani 1213,

Dhaka, Bangladesh

E-mail: shamsitasdidaa@gmail.com

Orchid ID: https://orcid.org/0000-0002-4835-2107

\section{Introduction}

$\mathrm{T}$ here are about 1000 platforms which drill under the sea in the Middle East. It can be disastrous if any accident occurs. The impact can be related to the environment, economy, as well as human injury and death. 
Ergonomics (or human factors) is the educational stream dealing with the understanding of the link between human beings and other parts of a system, and the study which applies theoretical basics, logics, information, and other processes to draft for optimization of well-being of human beings and full performance of the system. "Human error" is closely associated to accidents.

\section{How oil rig workers interact with machines}

We need to learn how the human being acts with the parts of the system and then put forward this knowledge to design of machines so that the total system is much safer, efficient and more useful. Some of these applications can be field agnostic, as the way the human being associates with certain processes and systems does not differ by field or domain. For example, we know that the visual differentiation between text and background determines how something is read. For instance, if yellow text is presented on a pale or white background, there is bound to be a negative impact on performance irrespective of the display being on an oil rig, a plane dashboard, or any other workspace. But in some fields, the parts of the system can be specific and therefore will need specific system related examinations and implementation of the reciprocity between the human being and the system to promote a design which is effective. Some fields of work have been blending human factors (HF) principles, methods, and materials for a long time.

In context of drilling of oil, some work has been done in blending human factor into oil and gas in the Gulf of Mexico by different stakeholders ${ }^{17,} 19,20$. But, there has been no methodological blending into the building, distribution, performance, and closure of the oil and gas rigs outside the UK.

The barrier now is to find how much information there is, how acceptable it is in terms of science and to link why the information has not been fully implemented in the industry. This paper intends to provide a gist of the available content on the situation of the oil and gas industry with link to the blending of human factor methods, principles, and processes.

\section{Basic elements in oil field drilling}

The three main and most basic elements required in the oil field drilling include the top drive, mud pumps and the draw-works. The main function of the mud pumps is to pump the mud mixture from the tanks into the drill pipes, which is used for cooling, lubrication and cleaning up drill cuttings. The top drive is used for rotating the drill string so that the drill bit cuts into the underground formation and it also provides the means for the mud to enter the drill string at high pressure. The draw-works is basically hoisting equipment used for raise or lowering the top drive during drilling and tripping operations. All of this equipment is controlled through the driller's console which is located in the driller's cabin.

The aim of this paper is also to evaluate and analyze the tele-operator system implemented in the driller's cabin of an offshore jack up rig.

Investigation has been done on the various incidents that took place in drilling operations from an ergonomic standpoint and provide recommendations that will aid in creating a better working environment.

\section{Operation of a Drilling rig}

In most of the modern rigs, operations are mostly done automatically, but there is still a considerable amount of human-machine interaction taking place during the process of these operations. Despite recent advances in the automation of drilling processes in offshore drilling rigs, there is still a considerable amount of human machine interaction taking place on a daily basis. Inside the driller's cabin, the driller controls the drilling process while the roughnecks assist him/her with adjustment of drill pipes. The need for a constant feedback from a human (driller) throughout the drilling and tripping sets it apart from the many other forms of tele-operations found in the oil and gas industry nowadays.

Conventional driller's consoles present all of the data and control mechanisms for every element of drilling machinery to the driller and assistant driller at all times. This includes draw works, mud pump, top drive and rotary table controls along with various forms of indicators, alarms and gauges. It is quite rare to have each of these components manufactured by the same company and therefore often the controls are all integrated into the consoles together with little regard to ergonomics and overload of information. , $^{3,5}$

\section{System description}

Figure 1 demonstrates an offshore jack up rig. This type of rig, when goes under major overhauling, usually consists of old generation equipment mixed in with new improved technologies. Usually, the driller's cabin contains the driller's console which is used to control various major drilling equipment in the rig. 


\section{Top Drive}

Top drive system (TDS), shown in figure. 2 is used to rotate the drill string while drilling, which allows the drill bit at the end of the drill string to cut into the ground formation. The average rating of top drives used in the drilling field is around 1000 horsepower. The driller can adjust the torque and speed of the rotation of the drill string through the driller's console. The top drive assembly is suspended from a hook just below the travelling block and is able to move up and down the derrick with the help of the draw works system. Another main feature of the top drive is the link tilt assembly which allows the pipes to be connected or disconnected from the pipe racking area. The link tilt system makes use of hydraulic cylinders and therefore a hydraulic pressure unit is available on the drill floor to provide pressure for the cylinder actuations ${ }^{6}$.

The top drive rarely requires input from the driller and is mostly automated. However, in older generation rigs, the pipe makeup or breakup requires the driller to manually control the draw works and the top drive with aid of the floor men and the derrick man to assemble the drill pipes. This process involves the use of various selector switches as shown figure.2. Although the top drive system comes with various interlocks to minimize human error by accidental operation of the various features like turning off the internal blow out preventer (IBOP) while no drill pipes are connected, caution must still be exercised because these interlocks can be easily overridden for maintenance purpose or simply due to malfunctioning equipment.

\section{Draw-works}

The draw-works demonstrated in fig. 4 is hoisting machinery used to raise or lower the travelling block which is in turn connected to the top drive. The drawworks function by the use of 2 motors, disc braking system, Baylor eddy current brakes are also used. When raising the traveling block, the draw works drum reels in the wire rope by turning on the motors which in turn rotate the gear system and transmit rotary energy to the wire drum. The gears used usually have two speed combination, i.e. low speed gear and high speed gear. This can be adjusted by the driller using the driller's console. During the lowering of the block the driller releases the breaks to allow the travelling block to the come down using its own weight. The speed of the lowering is determined by degree of brake released, (the lowering speed is highest when break is fully released), and the Baylor brake is used for smooth deceleration of the load when coming to a halt ${ }^{7}$.
During drilling, the draw-works is in auto driller mode and does not require any input from the driller. However, during tripping operations, the driller must continuously operate the draw-works. In fact, the draw-works is the equipment that driller manually interacts with the most and therefore it makes it critical equipment in the ergonomic evaluation in this paper. The draw-works holds the load of the entire drill string and therefore any malfunctioning can lead to the top drive falling on the rig floor injuring personnel and leading to stuck pipes. This is usually prevented by automatic prevention systems like the anti-two block system and the kinetic energy monitoring system (KEMS). However, during maintenance modes and special circumstances these systems can be overridden from the driller's cabin itself. The brakes of the draw-works are controlled by a joystick that releases the break when pushed forward. On the joystick a trigger button is used as a dead man switch and it needs to be always pressed when the joystick is being operated. If the driller lets go for the joystick, the dead man switch is no longer pressed and the parking brakes on the draw-works engages to prevent the travelling block from falling down. The driller pushes a pedal with his/her foot to rise the travelling block much like how one would press the gas pedal in a motor vehicle to accelerate.

\section{Mud pump}

Figure 5 shows a typical Mud pump in action. Drilling makes use pressured mud to cool and lubricate the bit that is cutting the downhole formation and at the same time the returning mud carries the cuttings back with it to the surface which prevents the well from clogging. Another major purpose of the mud is in well control, the hydrostatic pressure of the mud ensures that pressurized crude oil or gas in the reservoir does not come up to surface in the event of a kick, which can lead to an uncontrolled blowout. This mud is supplied under pressure by the mud pumps, which are piston actuated pumps that pump the mud from the mud pits into the drill string via the top drive. The mud pumps are actuated by electric motors and the speed can be controlled by the driller either locally or through the driller's console ${ }^{8}$.

The driller controls the pressure of the mud pump by rotating knobs which is also demonstrated in figure 13. placed on the driller's console and the pressure and the strokes per minute of the pump can be monitored through a gauge and an LCD panel in the driller's cabin. 


\section{Methods}

The findings reported in this paper are based on a structured, in-depth qualitative case study of two different employees involved in operating the drilling operations conducted in the driller's cabin of newly designed offshore rigs.

The information is intended to help in analyzing the ergonomic safety of the human interactions taking place in the driller's cabin. The study was part of a project exploring the ergonomics and human factors of oil rig workers. The aim of the study was to develop a thorough and systematic account of oil rig workers practices, providing a baseline to inform the development and evaluation of subsequent interventions. A case study was chosen as the methodological approach because these are well suited to developing an in-depth understanding of contexts and issues. The emphasis here is on the identification and description of issues as identified and understood by the oil rig workers and the machine usage positives and negatives. Such cases can also contribute to theory refinement by generating interpretations, which can be useful in limiting other generalizations or identifying areas of complexity that warrant further study.

The investigation had been conducted by collecting relevant data. Most of the data was collected from equipment manuals, drawings and possible photographs of the human machine interface. This has been the approach to better insight into the working of the drilling equipment. Furthermore, an attempt has been done to look into any previous incidents on the drill floor that possibly happened due to a human error. Lastly, the gathered data was evaluated from the human ergonomics standpoint and suggestions have been provided to compensate for any shortcomings found after the evaluation.

\section{Study Settings}

Both the workers are based in the Middle East where the latest cyber-rigs are located. Current estimates place the Middle East's conventional oil at about 800 $\mathrm{Bbo}$, or nearly half of the world's proven recoverable crude. The Middle East is unique for the concentration of numerous giant fields in the region.

\section{Data collection methods}

The analysis in this paper draws on the interviews conducted with two different employees involved in operating the drilling operations conducted in the driller's cabin of newly designed offshore rigs. A semi- structured approach was adopted, using themes identified through analysis of the preceding focus groups and visual mapping work. The interviews were conducted by two researchers, one working in the Middle East at that time and one from Bangladesh. The researcher in the Middle East had spent time working to develop sensitivity to the local oil rig workers and issues prior to beginning the interviews. Sections of the interview were dropped where these were not relevant to the interviewee. This provided consistency across participants whilst remaining flexible enough to respect the time and interests of those being interviewed.

\section{Data processing and analysis}

The interviews were transcribed by the research team. Each interview was analyzed thematically. Transcripts were reviewed and exhaustively coded following a systematic process and anonymized by replacing names with a tag, including reference to the field site. Coding was crossed checked by two researchers, leading to refinement of the coding method. The coded extracts were then grouped and summarized. The relationship between code groups was considered, in some cases leading to the amalgamation of separate categories under super coordinate groups. There are basically six groups on which the study has been divided. Mainly the people in the rig floor work in 3 shifts and either they do drilling or tripping. Table 1 describes their timing and work schedule.

Table 1: works at rig floor

\begin{tabular}{|ccl}
\hline Timing & Job going on & Location \\
\hline 12 AM-12 PM & Drilling & Rig Floor \\
\hline 6 AM- 6 PM & Drilling & Rig Floor \\
\hline 6 PM- 6 AM & Drilling & Rig Floor \\
12 AM-12 PM & Tripping & Rig Floor \\
\hline 6 AM- 6 PM & Tripping & Rig Floor \\
6 PM- 6 AM & Tripping & Rig Floor \\
\hline
\end{tabular}

An important consideration was the relationship between routine and exceptional incidents: it would have been possible either to describe normal practice first, and then exceptions to it; or else to describe both normal and exceptional incidents of each kind of practice. The final decision was the latter, giving an overview of oil rig workers practices, and within each, describing both normal and exceptional incidents. The information was gathered to perform an in-depth analysis from an ergonomic standpoint related to the tele-operation performed in the driller's cabin. 


\section{Ethical considerations}

The study followed the ethical guidelines of qualitative studies, both of which required informed consent, guarantees of confidentiality and anonymity for participants, and the right of participants to withdraw and have their data removed. Care was taken to ensure that all participants understood that they were acting as volunteers and were under no obligation to participate in the project. To avoid the influence of power relations on disclosure, the interviewers held no structural position in relation to interviewees, and in addition, the recordings and transcripts were kept confidential and anonymized, so that those with authority over participants had no access to the data set. The ethical protocol, including briefing sheets and informed consent forms, received approval from the lead institution's ethical review board.

\section{Findings}

\section{Observation of equipment, linking to experience}

The following have been provided in details in the interview section. The various comments and suggestions that were mentioned by the employees concerning the ergonomics of the driller cabin have been highlighted as well. Therefore, it helped to provide an overall feedback to the system as a whole in order to reach to a concluding verdict concerning the design of the renovated system. The renovated system is shown in figure 6 .

The interview focused on three main points of discussion:

1. Review on the tele-operator system: ergonomically

2. Design of various knobs and switches

3. Placement of various utilities inside the driller cabin

Interviews have been described separately along with comments and feedback on the ergonomics of the utilization of the various utilities available in the driller cabin in details.

\section{Evaluation of hardware}

\section{Dial Gauges}

The basic features of the scale have been shown in figure 7 . These are scale range; numbered interval and graduation interval are fair enough. Also, it is the preferred type of qualitative display; moving pointer against fixed scale.

The interviewees stated that the main readability issue is present, but the pointer is overlapping the scale numbers. As a result, more time is required by the worker in recognizing the hidden number through looking at the number before or after.

The scale graduation is not compatible with people expectation as numbers increase counter clock wise. This can lead to wrong interpretation of the hidden number and/or consume more time.

\section{Control levers}

In figure 8 the picture of draw works controller is provided. It can be seen that all the control levers look the identical, only distinguishable by labels which is a problem if fast control is required. Also, no feedback about the control status has been provided like (on/ off) (open/close). The Baylor brake lever shown in figure 9 is however different in length and color, which is appropriate because it is used the highest number of times. The handles are all pneumatic and therefore the driller receives haptic feedback when switching between two positions. The direction of the levers is also marked appropriately and it is generally established that "up" is the activated position, this is consistent with all the levers.

\section{Alarm Panel}

The alarm color shown in figure 10 is only limited to green and red. Red means running and green means stopped. This presents a problem for dichromate $(8 \%$ of the male), where they suffer from red and green cones and can't distinguish between the two colors McCormick et al. ${ }^{4}$ In Addition, multiple alarms are sharing same color which might be confusing. There are no indication of an idle state which is an important part of any operation.

\section{Control Panel}

Figure 2 shows the picture of the control panel present in the work area of the driller. The position of the control panel on such place makes it difficult for the operator to reach hence consumes more time for control. This can be deduced from fits law, where it says the movement time is proportional to the distance of movement from start to target center.

All displays and controls are labeled with good spacing. But most labels are located below the controller which will be blocked by driller's hand. Also there exists an issue with the coding system. C1, C2, C7, C13A, C13B and $\mathrm{C} 14$ are almost the same. It is only distinguished by labels which is a problem if fast control would be required. 


\section{The emergency stop button}

The location of the emergency button is good enough to avoid activation by mistake. This is demonstrated in figure 11. However, detectability of the button is a concern. The size and the color of the button should be modified for a better detectability.

\section{Labeling}

It is good that all displays and controls are labeled and placed above them. However, the labeling of displays and controls (the minimum requirement for coding) is missing which is major topography features: visibility and readability.

Width to height ratios found to be approximately $3: 5$

$\mathrm{H}=1.5 \mathrm{~cm}$

$W=1 \mathrm{~cm}$

Stroke width $=0.2 \mathrm{~cm}$

Stroke width to height ratio $=1: 7.5$ which is between the acceptable range of $1: 6$ to $1: 8$ for black on white typography (ISO-11064) ${ }^{15}, 16$. The letters are in uppercase letters, according to McCormick et al ${ }^{4}$ lower case letters are easier to read.

\section{Rotating Knobs for mud pump control}

Mud pump is one of the most important equipment of a drilling rig. It is usually controlled by the driller and mud is being pumped by this into the hole. The control in figure 6 is located in the driller's console. Beside many operational indicators there are four rotating knobs at the bottom panel which is shown in figure 12. All the four knobs look exactly the same which might lead to confusion and wrong selection of control knob.

\section{Reflection regarding ergonomics and human factors of workers via Interviews}

\section{Interviewee 1: Driller working on a 12 hour shift}

The first interview was conducted with an employee working as a driller on a 12 hour shift. The employee worked on the old designs of the offshore rigs for four years and then was transferred to the newly designed offshore rigs which helped in providing good points of comparison between the old and new designs from a dedicated user. The employee started by firstly providing his feedback on the tele operator being utilized. The employee indicated that the newly designed driller cabin is way more user friendly when compared to the old driller cabin. The employee mentioned that since the renovated design of the driller cabin is based on touch screen control rather than physical movement to execute drilling operation commands, the physical effort to execute these various commands is obliterated, making the new renovated system more ergonomic and user friendly. Moreover, the driller stated that the tele operating software being utilized has been very easy and user friendly and is very flexible in terms of providing different commands when it comes to overriding or cancelling unwanted commands.

The next point that has been discussed in the interview is the design of the knobs and joysticks available in the driller cabin in terms of its sensitivity and comfort of use. As for the shapes of the knobs, the widely known selector switch is being used as shown in figure 13

The driller indicated that the existing selector switch being utilized is of perfect use as it's free of any complications. Moreover, the driller stated that the use of the selector switch to execute required commands

As for the joystick that is being utilized, it is shown in figure 13 along with the tele operators involved.

The joystick is mainly utilized to control the widely known top drive which is responsible for carrying out the drilling operations. The two main parameters of the top drive that are ought to be controlled are the speed of movement and rotational torque. According to the driller, the sensitivity provided by the joystick is quite impressive as it provides the right feels to the user in terms of controlling the speed of the top drive. Moreover, the driller indicated that controlling the torque of the top drive through the tele operator is very responsive and that the feedback of the initiated command is almost instantaneous, making it superior to the old rig control methods which were stated to be quite slower in terms of its response.

Last but not least, the driller concluded the interview with a satisfactory inference overall. He mentioned two important points in his conclusion. Firstly he mentioned that the viewing angle of the tele operator screens were very satisfactory as they were adjustable to the viewer's relief as well as being inclined to his desired vision angle. The second point mentioned in the conclusion is that the driller's chair is adjustable to suit the driller needs in terms of both comfort and wellbeing at work. 
Interviewee 2: Assistant Driller from an Offshore Rig

The second interviewee regarding the well-being of the driller's cabin involved an assistant driller that worked on a 12 hour shift on one of the offshore rigs in the Middle East. This interview was slightly different than the first as it involved the discussion of situational issues that has occurred over the course of the 2 years the interviewee has spent on the rig. The name of the rig is not to be mentioned for confidentialities as an incident occurred on that specific rig is to be discussed. As described by the interviewee, the incident that has occurred is as follows.

The assistant driller was operating the top drive on a specific speed and was operating it to move upwards using the joystick provided. The top drive has a link "tilt command" that can be operated in order to extend or retract the link of the top drive whenever necessary. The assistant driller relied on the zone management system that is provided by the tele operator for guidance on the fact that the link tilt is to hit equipment while the top drive is moving back down or not. But the assistant driller was unaware of the fact that the zone management system is not to indicate such a warning due to the fact that equipment parts such as the link tilt is not a part that is governed by the zone management system. The link tilt has therefore hit the monkey board which caused some drilling pipes on the monkey board to move from its place, but luckily no pipes has fallen or caused any damage to any of the surrounding workers. As for the link tilt, it had to be repaired before it became ready to its normal operating mode.

Two main points were indicated in the incident report that was produced:

\section{Root Cause 1: Complacency and Reliance on the ease of operation}

As much as the teleoperator touch screen mode of operation seem handy and reliable, that doesn't mean that caution and attention is not to be taken into consideration. The interviewee elaborated that the new renovated system feels easy to handle in terms of execution of commands, however the operator should always be aware of his zone of operation and not rely on the teleoperator in every operation or command he is to execute.

\section{Root Cause 2: Resting Intervals is to be Situational}

Due to the fact that the assistant driller is working on a 12 hour shift with only three breaks that occur after every four working hours, he shouldn't be stressing himself when it comes to stopping for taking a breather whenever possible. It can be associated that the cause of this incident has been the lack of concentration, which was mainly caused by the psychological pressure the assistant driller was suffering from due to the lack of a proper resting interval. The policy of the company usually provides its employees with proper break intervals as verified by a lot of employee; however this does not mean that a working employee is not to take a break whenever needed in order to avoid such incidents from occurring every now and then.

The assistant driller concluded with an overall satisfactory feedback about the new renovated system being utilized in the cyber rigs driller's cabin. He stated that the tele operator was ergonomically comfortable and that executing commands have never become easier. However, his emphasis was on the fact that new operators have become very reliable on technology and on the advancement of the various warning mechanisms. This therefore creates a sense of complacency in the newly hired employees, as this decreases their attention after getting used to the newly renovated system due to the fact that it's easy to use with no effort needed even when performing difficult commands.

\section{Linking of observations and experiences}

It is found that the drillers console complies to most of the ergonomic standards with a few exceptions where the team has given recommendations to overcome the shortcomings. The main readability of dial gauges is present. Control levers are only distinguished by labels which is a problem if fast control is required. These can be enhanced by color coding. The alarm panel is only limited to red and green which is a problem for dichromate operators. The emergency stop button size and color should be modified. The labeling of displays and controls (the minimum requirement for coding) is missing major topography features: visibility and readability. 


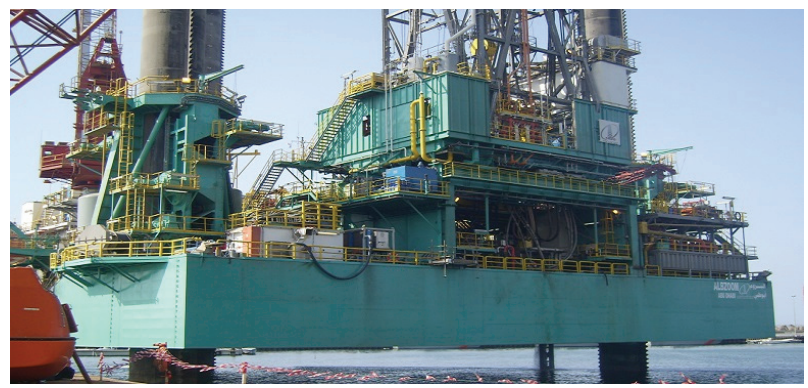

Figure 1: Jackup rig

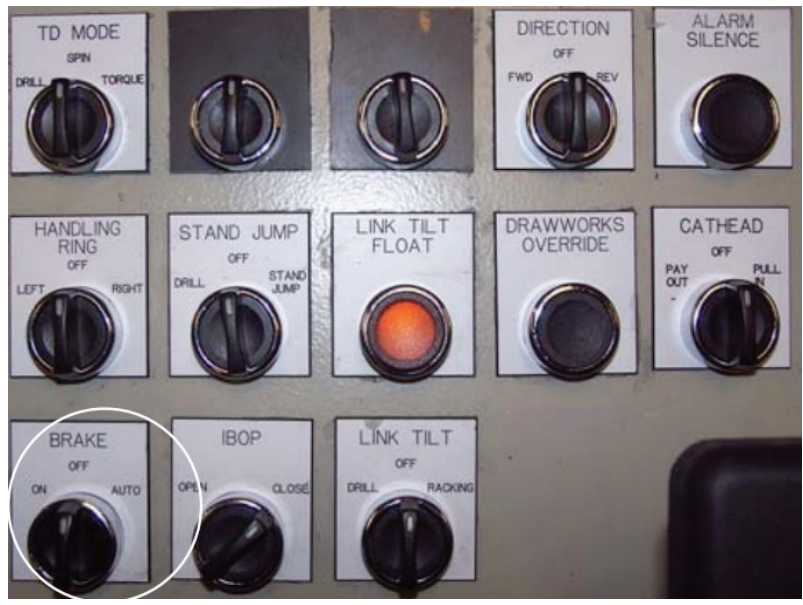

Figure 2: Top Drive control panel in drillers console

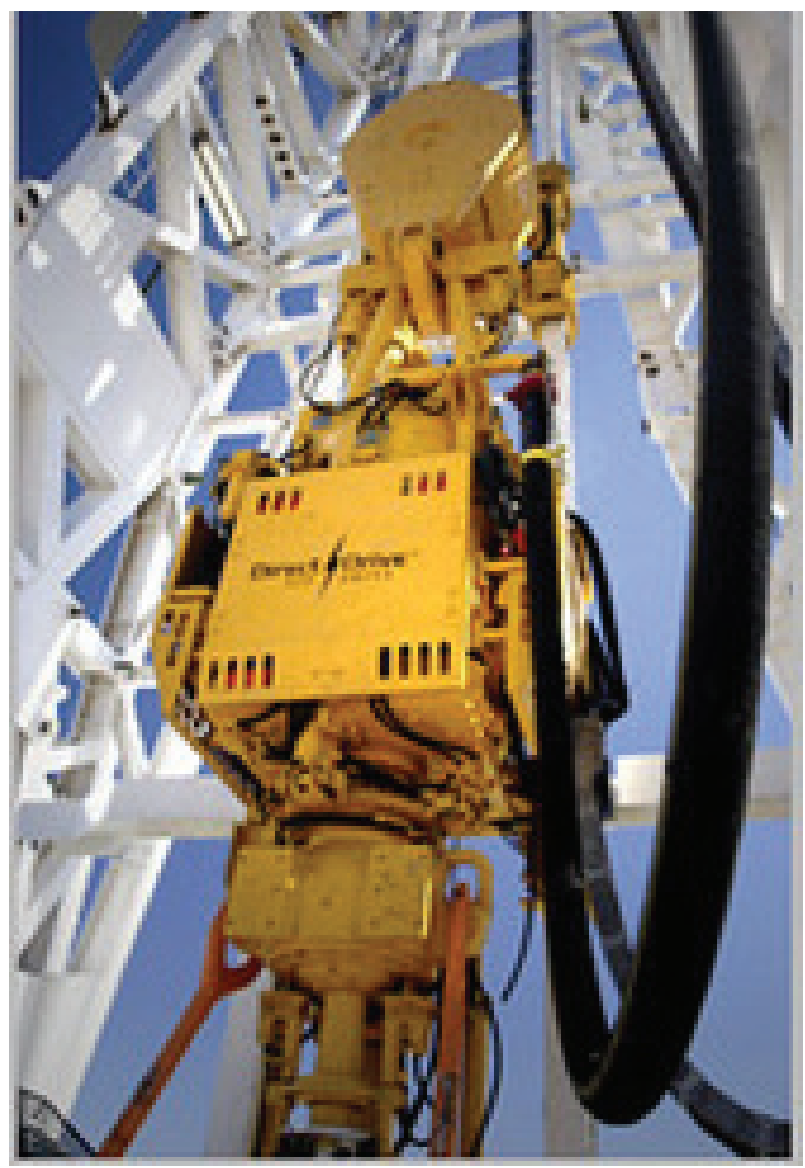

Figure 3: Top Drive

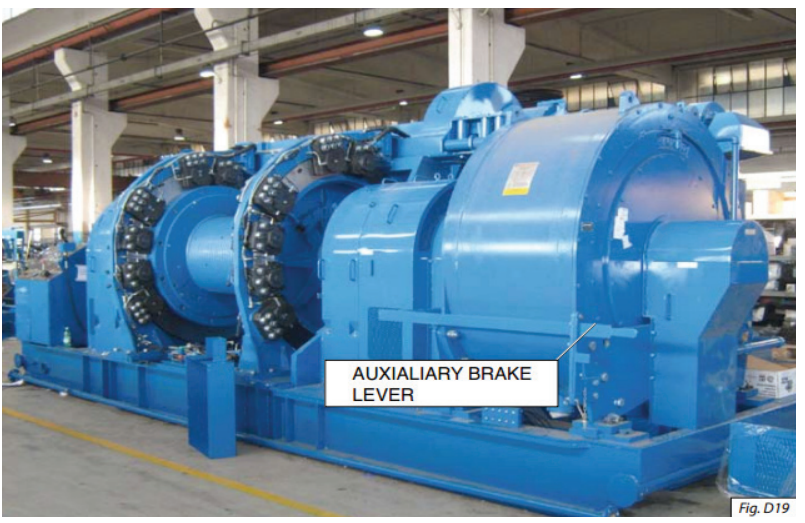

Figure 4: Draw works (DW) in offshore drilling

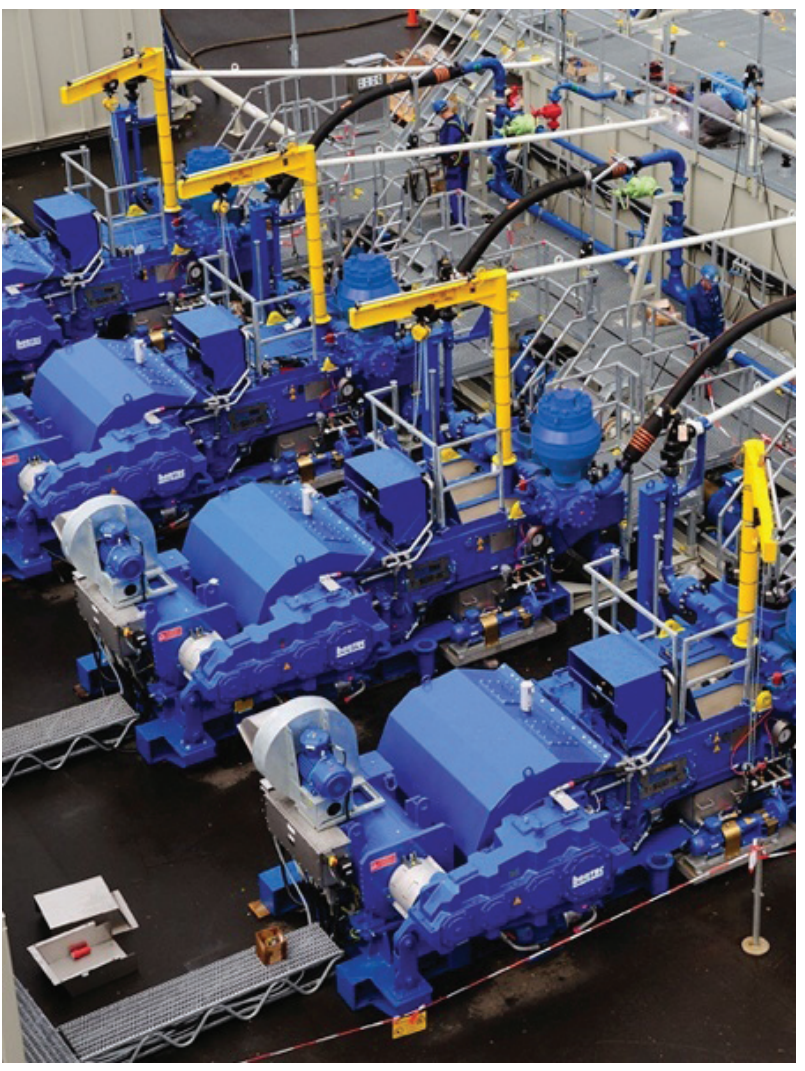

Figure 5: Mud pumps

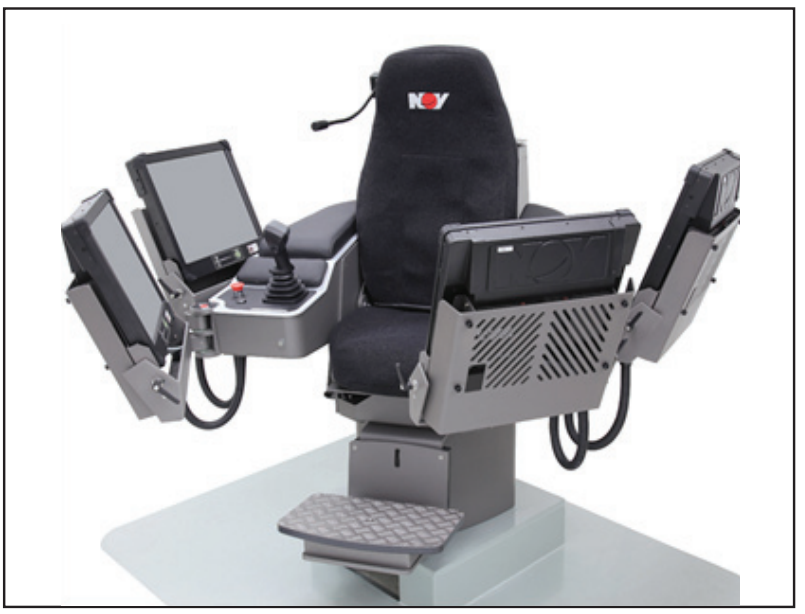

Figure 6. Renoveted drillers console (NOV) [19] 


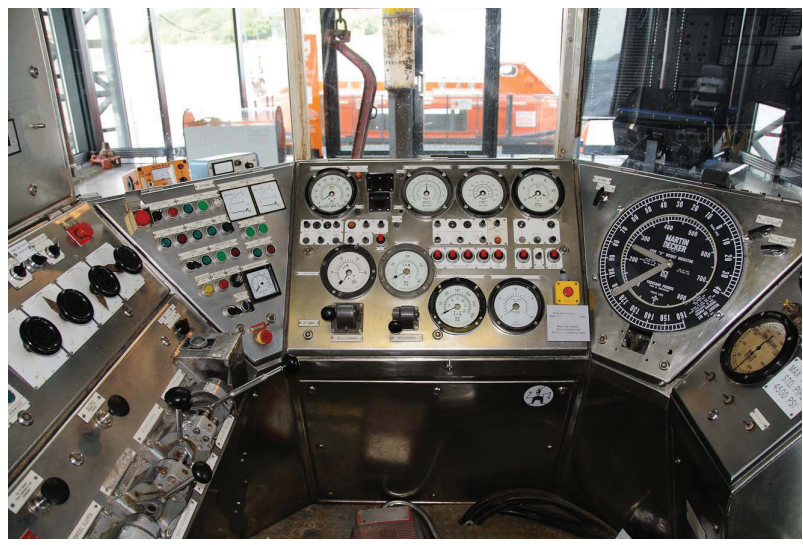

Figure 7: Dial gauges in the drillers cabin

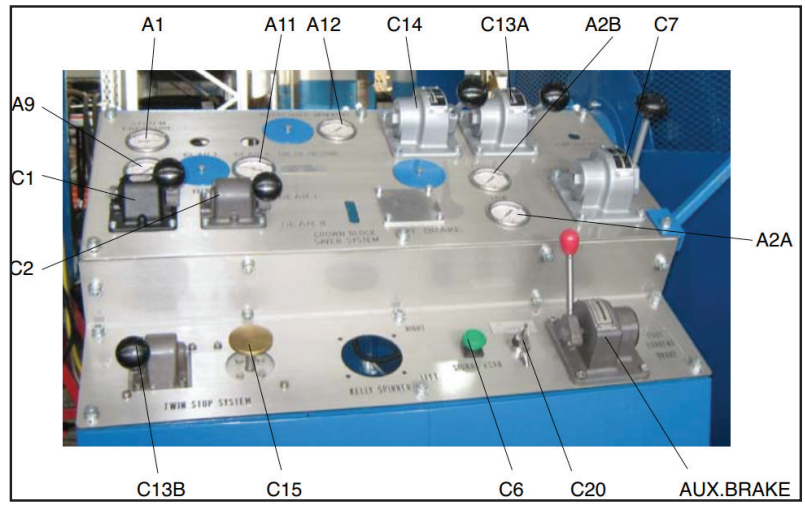

Figure 8: Drawworks control in the drillers cabin

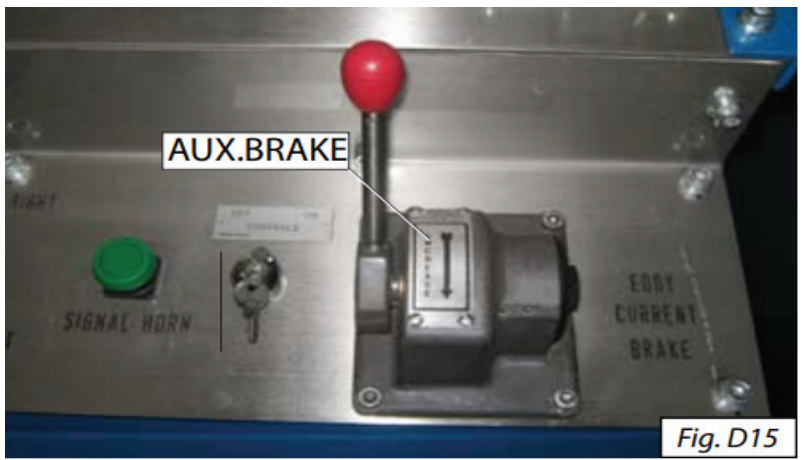

Figure 9: Auxallary brake

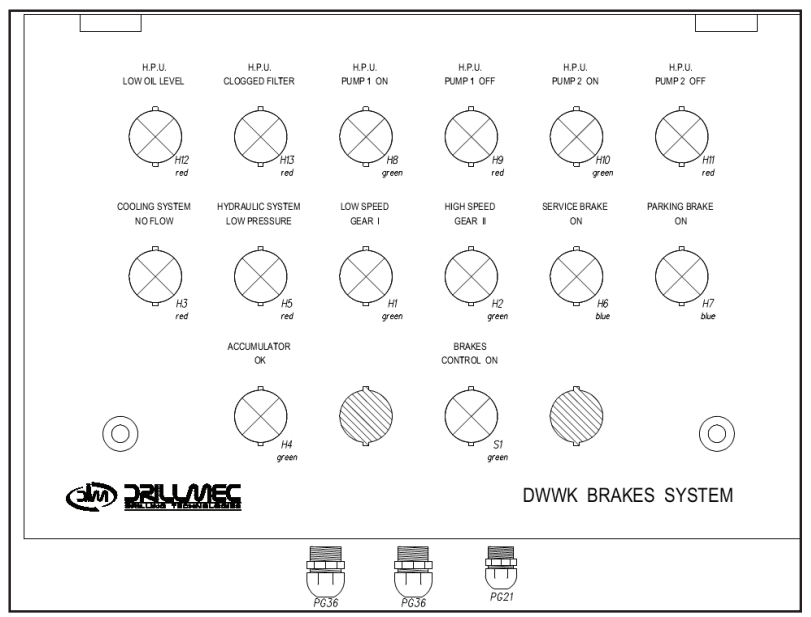

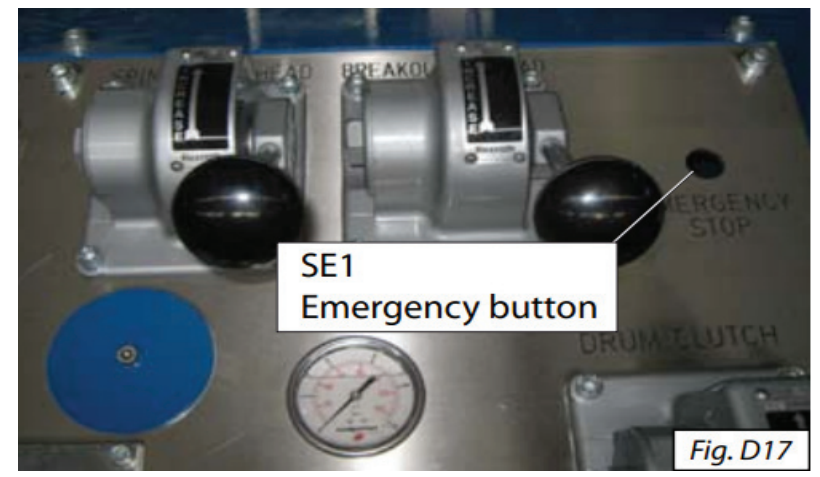

Figure 11: Emergency stop button for the operation

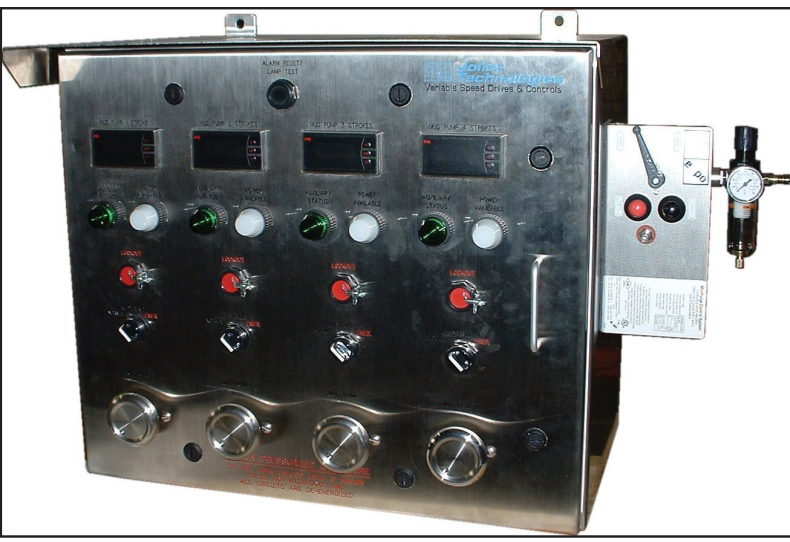

Figure 12: Mud pump control center

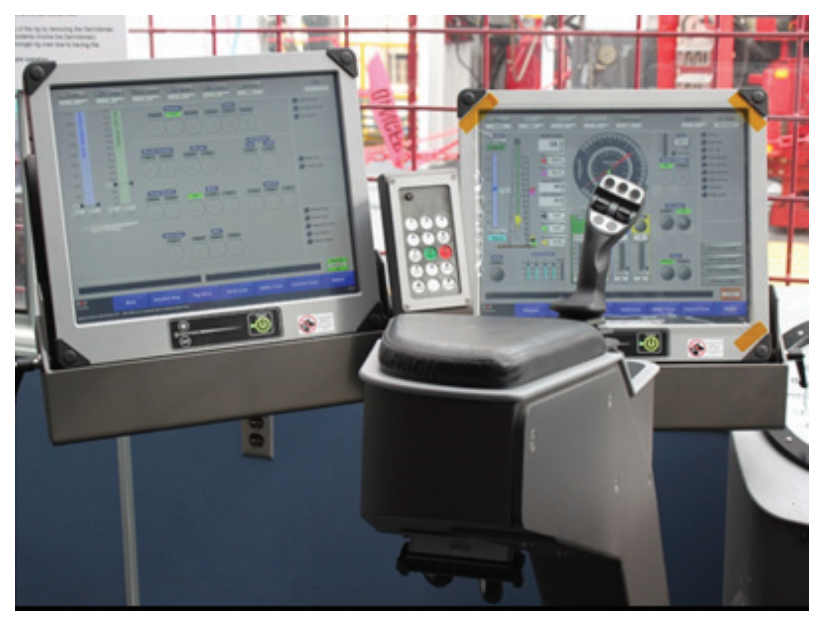

Figure 13: Joystick (TD control) and HMI at the drillers cabin

\section{Discussion}

There have been several studies conducted on offshore oil-rig workers, where not much focus has been put towards human machine interface but more on shift work, management of health hazards, exposures to cancer etc ${ }^{19,20,23}$

Figure 10: Alarm panel in the drillers cabin 
When compared to a study by Rassenfoss, it was reported that workers have to put a lot of physical effort towards drilling simulation. ${ }^{21}$ Our study can be modified to find how drilling simulation can be improved by linking with the recommended human machine interface.

In our study, when comparison is done with the existing machinery, few modifications can be thought of for better human machine interaction. This study can also follow another research conducted on accident reporting on modifying reporting of problems with machines. ${ }^{15}$ The main beauty of our study is within knowledge no study focusing on just human machine interaction linking to design of machinery has been conducted till now.

Dial Gauges need to have gauge with thinner pointer, use different pointer color than frame color to allow easy reading from distance. Clockwise increasing scale for more compatibility is important to prevent "habit interference", prevent faster reaction time, less errors and higher user satisfaction.

The control levers' shape should be changed in such a way that it resembles the element being controlled. The labels should be arranged in such a way above the control so that the worker's hand does not hide and cause problem with visibility. There should be arrows to tell which direction the controller should be moved. Different textures should be used especially for controllers close to each other.

The alarm panel should have different shapes, rather than just circular shapes. Different alarm colors such as white and yellow should be used.

Control panel lever shape should be changed in such a way that it resembles the element being controlled. The size should be as such that it is proportional to the element being controlled. The labels should be arranged above the control. Different texture should be used especially for controllers close to each other. The control should be located in closer proximity of the operator. The designing of the system for the majority of the population control panel should be on the right side of the operator. All the screen should be located close to each other so that one does not have to look all over the place.

The emergency stop button should be set in such a way that the code is detectable. The larger font with bright color will have more contrast ratio. The color coding should be meaningful like red in case of emergency stop.

The visibility of the labels should be enhanced through changing the color of the font or panel background. Small white sheet should be provided for each label along with bigger font with lower case for easier reading.

Rotating Knobs should enhance the identification of knobs by using shape coding and shifting from flat texture knobs into non-flat ones.

Thus, the idea is to understand how the human interacts with the elements of the system and then apply that understanding to design in order to make the system safer and more effective.

Various offshore and onshore drilling control panels have been evaluated keeping the ergonomics aspect in mind. It has been found that distinguishing between displays and controls is mainly dependent on labels which are not practical if fast control is required. Also, it has been found that alarms are highly dependent on visual signals. However, it is always recommended to use different dimensions rather than different levels for the same dimension. Therefore, it is recommended to utilize auditory signals and alarms especially for conditions that donate danger.

\section{References}

1. Bias, R. G., \& Gillian, D. J. Human error: But which human. Disaster Recovery. 1997.10(3): 43-4.

2. Michel, J., Owens, E. H., Zengel, S., Graham, A., Nixon, Z., Allard, T., \& Rutherford, N.. Extent and degree of shoreline oiling: Deepwater Horizon oil spill, Gulf of Mexico, USA. PloS one. 2013. 8(6). Available from : https://journals.plos.org/plosone/ article? id=10.1371/journal. pone. 0065087

3. Harbour W. D., J. Kracik, and D. Ford, "An ergonomic, process oriented approach to driller's consoles,"

IADC/SPE Drilling Conference, 1998. Available from : http://www.gbv.de/dms/tib-ub-hannover/243622317. pdf

4. McCormick E. J., Human factors in engineering, 7th ed. 1993. McGraw-Hill, New York: United stated of America.

5. Woldstad J. and J. Pesante-Santana, "Quality Inspection Task in Modern Manufacturing," International Encyclopedia of Ergonomics and Human Factors. [Available: http:// digitalcommons.unl.edu/cgi/viewcontent.cgi?article= 1010\&context=imsefacpub] 
6. “How Does a Top Drive Work?,". Rigzone. Available at: http://www.rigzone.com/training/insight.asp?insight_ id $=332$.

7. "The application of ergonomics to oilwell drilling rigs," Applied Ergonomics, 1990;21(4) : 337. Available from : file://C:/Users/DELL/Downloads/ preprints201810.0377.v1.pdf

8. Short J. A., Drilling: a source book on oil and gas well drilling from exploration to completion. Tulsa, OK: PennWell Books, 1993.

9. Graham, B., Reilly, W., Beinecke, F., Boesch, D., Garcia, T., Murray, C., \& Ulmer, F. The National Commission on the BP Deepwater Horizon Oil Spill and Offshore Drilling. Deep Water. The Gulf Oil Disaster and the Future of Offshore Drilling. Report to the President. (2011). Available from: https://www. govinfo.gov/content/pkg/GPO-OILCOMMISSION/ pdf/GPO-OILCOMMISSION.pdf

10. Management of health and safety at work, approved code of practice. Management of Health and Safety at Work Regulations 1999. Approved Code of Practice \& guidance. Health and Safety Executive. Available from : https://www.hseni.gov.uk/sites/hseni.gov.uk/ files/publications/\%5Bcurrent-domain $\% 3$ Amachinename $\% 5 D / / 21$-management-of-health-and-safety-atwork_0.pdf

11. The Explosion and Fires at the Texaco Refinery, Milford Haven, 24 July 1994 (Incident Report): 1997. Health and Safety Executive. Available from : https:// jesip.org.uk/uploads/media/incident_reports_and_ inquiries/Texaco\%20Refinery\%20Explosion.pdf

12. RR-1. Human factors integration: Implementation in the onshore and offshore industries Research Report 001, Prepared by BAE Systems Defense Consultancy: UK. 2021 Health and Safety Executive. Available from : https://www.hse.gov.uk/research/ rrhtm/rr001.htm

13. The development of a fatigue/risk index for shift workers; research report 446.2006. Health and Safety Executive. https://www.hse.gov.uk/research/ rrpdf/rr446.pdf

14. John Hare, Michael Johnson .Underlying Causes of Offshore Incidents, FP/09/21: 2009 Health and Safety Laboratory. Available from : https://www.hse.gov.uk/ offshore/offshore-incidents.pdf

15. Gordon, R. P. The contribution of human factors to accidents in the offshore oil industry. Reliability Engineering \& System Safety. 1998;61(1-2):95-108. Available from : https://www.nrc.gov/docs/ML0906/ ML090650437.pdf
16. ISO-11064. (2013). Ergonomic design of control centres -- Part 4: Layout and dimensions of workstations, ISO 11064-4:2013 International Organization for Standardization. Available from : https://www.iso.org/standard/54419.html

17. ISO-11064-1. (2010). Ergonomic design of control centres - Part 1: Principles for the design of control centres, ISO 11064-1:2000(en): International Organization for Standardization. Available from : https://www.iso.org/standard/19042.html

18. Miller, G. (1999). Human Factors Engineering (HFE): What It Is And How It Can Be Used To Reduce Human Errors in The Offshore Industry. Paper presented at the Offshore Technology Conference. Offshore Technology Conference Available from :https://onepetro.org/OTCONF/proceedingsabstract/99OTC/All-99OTC/OTC-10876-MS/39531

19. Niven, K., McLeod, R. Offshore industry: management of health hazards in the upstream petroleum industry. Occupational medicine. 2009; 59(5):304-9.

20. NOV Driller's Workstation RISE technology for CYBERBASE. Available from : https://www.nov. com/-/media/nov/files/products/rig/rig-equipment/ drilling-control-systems-and-rig-automation/novdrillers-workstation-rise-for-cyberbase-flyer.pdf

21. Rassenfoss, S. Drillers Find Themselves in a Tricky Spot at the Human/Machine Interface. Journal of Petroleum Technology. 2012 ; 64(05):48-54.

22. Robertson, N. L. Starting Right: Sable Offshore Energy Project's HFE Program. Paper presented at the Offshore Technology Conference 1999, Houston, Texas. Available from : https://onepetro.org/ OTCONF/proceedings-abstract/990TC/All-99OTC/ OTC-10877-MS/39564

23. Stenehjem, J. S., Friesen, M. C., Eggen, T., Kjærheim, K., Bråtveit, M., \& Grimsrud, T. K. Selfreported occupational exposures relevant for cancer among 28,000 offshore oil industry workers employed between 1965 and 1999. Journal of occupational and environmental hygiene. 2015;12(7) :458-68.

24. Thomas, J., Baker, C. C., Malone, T. B., Malone, J. T., Hard, C. L., Rezende, I. C., Caruana, S., \& Witten, M. 2002. Application of Human Factors in Reducing Human Error in Existing Offshore Facilities. Available from :

25. Waage, S., Moen, B. E., Pallesen, S., Eriksen, H. R., Ursin, H., Åkerstedt, T., \& Bjorvatn, B. Shift work disorder among oil rig workers in the North Sea. Sleep. 2009 ; 32(4): 558-65. 